\title{
MODELLING OF THE SELECTED PHYSICAL PROPERTIES OF THE FAVA BEAN WITH VARIOUS MOISTURE CONTENTS USINGFUZZY LOGIC DESIGN
}

\author{
VAHID FARZANEH ${ }^{1,6}$, ALIREZA GHODSVALI ${ }^{2}$, HAMID BAKHSHABADI $^{3}$, MOHAMMAD GANJE $^{4}$, \\ ZAHRA DOLATABADI ${ }^{5}$ and ISABEL S.CARVALHO ${ }^{1}$ \\ ${ }^{1}$ Food Science Lab., MeditBio, Faculty of Science and Technology, University of Algarve, 8005-139, Faro, Portugal \\ ${ }^{2}$ Department of Agricultural Engineering, Agriculture and Natural Resources Research Center of GolestanProvince, Iran \\ ${ }^{3}$ Young Researchers and Elites Club, Gorgan Branch, Islamic Azad University, Gorgan, Iran \\ ${ }^{4}$ Department of Food Science and Technology, University of Agricultural Sciences and Natural Resources, Gorgan, Iran \\ ${ }^{5}$ Young Researchers and Elites club, Sabzevar Branch, Islamic Azad University, Sabzevar, Iran
}

${ }^{6}$ Corresponding author:
TEL: + $351969018099 ;$
FAX: +351 289818419;
EMAIL: farzaneh1364@gmail.com
Received for Publication August 14, 2015
Accepted for Publication January 28, 2016

doi:10.1111/jfpe. 12366

\begin{abstract}
The current paper indicates the systematic determination of the optimal conditions for the selected physical properties of the fava bean. The effects of varying moisture content of the Barkat fava bean grown in Golestan, Iran, in the range of $9.3-31.3 \%$ (Input) on the 15 selected physical properties of the crop, including geometric values as such length; width; thickness; arithmetic and geometric mean diameter; sphericity index surface and the area of the image; gravity and frictional parameters like the weight of 1000 seeds; true density; bulk density; volume and porosity as well as friction (filling and vacating angle stability) as the outputs were predicted. Afterwards, a model relying on fuzzy logic for the prediction of the 15 outputs had been presented. To build the model, training and testing using experimental results from the Barkat fava bean were conducted. The data used as the input of the fuzzy logic model are arranged in a format of one input parameter that covers the percentage of the moisture contents of the beans. In relation to the varying moisture content (input), the outcomes (15 physical parameters) were predicted. The correlation coefficients obtained between the experimental and predicted outputs as well as the Mean Standard Deviation indicated the competence of fuzzy logic design in predicting the selected physical properties of fava bean seeds.
\end{abstract}

\section{PRACTICAL APPLICATION}

Today, because of the high demand for crops to be used extensively in the human diet, enhancements in the efficiency of the processing are getting more attention. In this way, finding and/or the determination of the optimal conditions for processing with minimum waste looks very substantial. Therefore, the use of prediction methods in food processing is considered to be a tool for improving the efficiency and the quality of the produced products. In this regard, the fuzzy logic design as a novel prediction tool, along with response surface methodology (RSM) and Artificial Neural Network (ANN), are applied extensively. Therefore Fuzzy Logic Design is optimized to predict the some of the selected physical properties of fava bean, as a function of seed's moisture content. Therefore predicting the behavior of this crop against different moisture contents can improve the quality and performance of the products with the minimum wastes during very short time.@ 2016 Wiley Periodicals, Inc 


\section{INTRODUCTION}

L. Vicia-faba, also known as the broad bean, field bean, faba bean, bell bean, fava bean or tic bean, is a vegetable crop originating from Fabaceae and generated by cross pollination. It originally comes from the Mediterranean region, south and west Asia and America. This product is mostly cultivated in Ethiopia, and some parts of South America. Recently, fava beans have attracted attentions from various groups of consumers from Europe, America and Australia. The fava bean is accepted as a nutrient source for human requirements and can also be used for feeding animals. Moreover, this crop contains bioactive compounds, making it an effective treatment for some diseases and for use as a preservative in food and even nutraceutical products (Baginsky et al. 2013; Farzaneh and Carvalho 2015; Kukić et al. 2015). Nowadays, this crop is cultivated in farms within the area of more than 300,000 hectares, and the proficiency of its harvest was reported as 5.5 tons/hectare (FAO 2005). Predicting the behaviors of products with different moisture content during processing could increase the proficiency of the manufacturing and quality of the products, as well as decreasing the waste in line product (Nakagawa and Ochiai 2015; Bouzembrak and Marvin 2016). In other words, preserving the quality of the products, reducing the transportation and processing expenses as well as finding novel methods to process various products requires obtaining information on their behaviors under various conditions using prediction systems. Geometric characteristics, including shape, dimensions, arithmetic and geometric diameters, surface curvature as well as bulk and true densities and porosity value are the most effectual parameters that influence the design or model of drying and conditioning of the seeds, because of these values influencing mass resistance against air flow. Mass density value plays a considerable role in the prediction of storage conditions, and the weight of 1000 seeds is an index in determining the equivalent diameter, and might be used in the estimation of the seeds' size and cleaning the seeds using an aerodynamic force method (Razavi and Akbari 2009; Razavi, Zayerzadeh et al. 2010). Some scientists have reported that the high moisture content of the seeds might diminish the mechanical damage to the seeds and therefore it could enhance the efficiency of food processing and the quality of the final products in the nutraceutical industries (Aviara et al. 2013; Romuli et al. 2015). In the food product industries, the lack of tools for the prediction of the behaviors of diverse products in different applied processes' conditions has ensured further complications in controlling the systems. Since existing critical control points (CCP) in line products are inescapable, discovering novel systems to overcome the deficiencies in the management of the line products therefore seems essential. These managing systems should have the capability to determine the optimal conditions for production and shift them to the management room (Perrot et al. 2000). Some scientists have exploited fuzzy logic design to propose a model to predict the best quality tomatoes regarding the organoleptic properties including color, size, shape and toughness parameters (outputs) (Goel and Sehgal 2015). In other investigations performed in 2001 by Davidson et al., fuzzy logic design was used to provide an automatic monitoring system based on the numerous physical properties of chocolate (outputs) (Davidson et al. 2001). The application of the fuzzy logic design, along with RSM and ANN, has been used in food process engineering (Rostami et al. 2014; Dolatabadi et al. 2016)The aim of this investigation is to introduce an effective and strong model in the predication of the extensive physical characteristics of the fava bean with various moisture content, with high precision during a short period time that could be exploited in the monitoring and management of the various stages of processing including harvesting, handling, grading, storage, etc.

\section{MATERIALS AND METHOD}

\section{Materials and Equipment}

Sample Material. The $20 \mathrm{~kg}$ of Barkat fava bean applied in the current investigation was purchased during three different days from the plant and seed preparation and improvement of the natural resources section in the agricultural center of Golestan, Gorgan, Iran. The collected samples were homogenized several times, and then each experiment has been performed in three replications to avoid from any errors in the obtained results.

Apparatus. The equipment used in this study include, the plate, burette, desiccator, beaker, glass rods, ruler, digital caliper (Chinese Model, with an accuracy of $0.01 \mathrm{~mm}$ ), digital scale (GEC AVERY, Model; T5 / NO286, with the precision of 0.01g), Oven (Memmert, Germany, model 600 D 06062), refrigerator and sealing machine.

\section{Preparation and Determination of Moisture}

The requested seeds for the experiments were manually cleaned, and then broken and damaged seeds as well as external particles were removed and preserved in polyethylene containers in the lab environment. The basic moisture content of the samples was determined regarding the method of ASAE NO 352.2 (1997) (Reference). To prepare the samples with higher moisture content in relation to the desired humidity content in accordance with our design in 
the experiment, the volume of distilled water added was computed through the following equation:

$$
W_{2}=W_{1} \times\left(M_{2}-M_{1}\right) /\left(100-M_{2}\right)
$$

where $W_{2}$ is the mass of the added deionised water $(\mathrm{kg}), W_{1}$ presents the primitive mass of the sample $(\mathrm{kg}), M_{1}$ indicates the primitive mass of moisture of the sample $(\mathrm{kg})$ on the basis of wet weight and $M_{2}$ is the final moisture content of the dehydrated sample on a wet basis (Tscheuschner 1987).

After adding distilled water to the sample and stirring the mixture in a polyethylene bag, the bag was sealed and preserved in the fridge under a temperature of $5^{\circ} \mathrm{C}$ for at least one week for a uniform distribution of the moisture. Before each experiment, it was essential to increase the temperature of the provided samples to room temperature. Therefore samples were left for a minimum of one hour before experiments were conducted at room temperature. All of the physical properties of the fava beans were carried out with five varying moisture content values and each experiment was replicated three times and recorded.

\section{Determination of the Geometrical Specifications}

Exploiting a digital calliper, dimensional characterisations including length $(L)$, width $(W)$ and thickness $(T)$ were recorded using 100 fava bean seeds which were selected randomly. Afterwards, regarding Eqs. (2-6), the arithmetic diameter $\left(D_{a}\right)$, geometric diameter $\left(D_{g}\right)$, lateral surface $(S)$, spherical $\left(S_{p}\right)$ as well as the image area $(A)$ values were computed (Tscheuschner 1987):

$$
\begin{gathered}
D_{a}=\frac{(L+W+T)}{3} \\
D_{g}=\sqrt[3]{L W T} \\
S=\pi D_{g}{ }^{2} \\
S p=\sqrt[3]{L W T}-\times 100 \\
A=\left(\pi L L_{1}\right) / 4
\end{gathered}
$$

In Eq. (6), where $L_{1}$ indicates the mean of length and width of the seeds or

$$
L_{1}=(\mathrm{W}+\mathrm{L}) / 2
$$

\section{Determining the Gravity Characteristics}

A digital scale with an accuracy of 0.001 was applied to determine the weight of 1000 seeds. To measure the bulk density $\left(D_{b}\right)$, according to Eq. (8), a hollow cylinder was filled with an apparent volume of the sample and afterward the density value was computed through dividing the bulk mass $\left(M_{b}\right)$ by the bulk volume $\left(V_{b}\right)$ (Kaleemullah and Gunasekar 2002). In order to assess the true density $\left(D_{r}\right)$, a nonabsorbent Toluene solution was used to specify the seams among the seeds and therefore the true volume was computed by subtracting the bulk volume $\left(V_{b}\right)$ from the observed seams. Through dividing the bulk mass $\left(M_{b}\right)$ by the true volume $\left(V_{t}\right)$, true density $\left(D_{r}\right)$ was determined, regarding Eq. (8). Next, the porosity rate (e) of the seeds was estimated in relation to Eq. (6).(Razavi and Akbari 2009).

$$
\begin{gathered}
D_{r}=\left(M_{b} / V_{t}\right) \\
e=\left(\left(D_{r}-D_{b}\right) / D_{r}\right) \times 100
\end{gathered}
$$

\section{Determination of Frictional Specifications}

To determine the angle of the discharge repose $(E)$, a threedimensional wooden box with dimensions of $12 \times 12 \times 12 \mathrm{~cm}$, equipped with a sliding door, was used. Initially, the box was filled with the sample. Then, through using a metal or glass blade in a zigzag motion (five times), the material inside the container was tangent to the surface of the container and afterwards, the sliding door was swiftly shifted up. After discharging the seeds, the discharge repose angle was estimated using the following equation:

$$
E=\tan ^{-1}(h / a)
$$

where $a$ equals $12 \mathrm{~cm}$ (dependent on instrument) and $h$ indicates the height of the bulk or piles created by grains discharged in $\mathrm{cm}$. The experiments were replicated five times, and the outcomes obtained were calculated as mean $\pm \mathrm{SD}$ (Tscheuschner 1987; Kaleemullah and Gunasekar 2002).

To evaluate the filling repose angle or the filling stability angle, a cylinder with a diameter of $100 \mathrm{~mm}$ and a height of $150 \mathrm{~mm}$ and a wooden plate with a diameter of $20 \mathrm{~cm}$ was operated. The cylinder was situated at the heart of the disc and filled with the samples. The samples' surface was smoothened by a glass rod in a zigzag motion (five times); henceforth the cylinder was gradually shifted upward by the sample to form a hill. At this point, the height of the hill was recorded. The stability filling angle $\left(F_{\theta}\right)$ was computed through the following equation:

$$
F_{\theta}=\tan ^{-1}(h / 10)
$$

In Eq. (11), $h$ is the height of the bulk created by seeds in $\mathrm{cm}$. Each experiment has been replicated five times and the outcomes were obtained as mean $\pm \mathrm{SD}$ (Kaleemullah and Gunasekar 2002). 
TABLE 1. TRANGULAR MEMBERSHIP FUNCTIONS OF GEOMETRICAL PROPERTIES OF FAVA BEANS EXPLOITED BY FUZZY LOGIC DESIGN FOR MOISTURE CONTENTENTS IN THE SELECED RANGE (9.25-31.27\%)

\begin{tabular}{|c|c|c|c|c|c|c|c|c|c|}
\hline \multirow{2}{*}{$\frac{\text { Variable }}{L(\mathrm{~mm})}$} & \multirow{2}{*}{$\begin{array}{l}\text { Memberships } \\
\text { name } \\
\text { VL }\end{array}$} & \multicolumn{3}{|c|}{$\begin{array}{l}\text { Parameters of membership } \\
\text { functions }\end{array}$} & \multirow{2}{*}{$\begin{array}{l}\text { Variable } \\
S_{p}(\%)\end{array}$} & \multirow{2}{*}{$\begin{array}{l}\text { Memberships } \\
\text { name }\end{array}$} & \multicolumn{3}{|c|}{$\begin{array}{l}\text { Parameters of membership } \\
\text { functions }\end{array}$} \\
\hline & & 22.71 & 22.81 & 22.91 & & & 0.600 & 0.602 & 0.607 \\
\hline & L & 22.86 & 22.96 & 23.06 & & L & 0.601 & 0.604 & 0.609 \\
\hline & $M$ & 23 & 23.02 & 23.2 & & M & 0.603 & 0.606 & 0.611 \\
\hline & $\mathrm{H}$ & 23.2 & 23.33 & 23.4 & & $\mathrm{H}$ & 0.607 & 0.624 & 0.649 \\
\hline & VH & 23.34 & 23.54 & 23.64 & & VH & 0.635 & 0.662 & 0.687 \\
\hline \multirow[t]{5}{*}{$W(\mathrm{~mm})$} & $V L$ & 16.7 & 16.79 & 16.87 & $D_{\mathrm{g}}(\mathrm{mm})$ & $V L$ & 12.95 & 13.65 & 13.7 \\
\hline & L & 16.75 & 16.82 & 17.14 & & $\mathrm{~L}$ & 13.62 & 13.77 & 13.92 \\
\hline & M & 17.1 & 17.2 & 17.4 & & M & 13.75 & 13.93 & 14.11 \\
\hline & $\mathrm{H}$ & 19.83 & 24.83 & 28.83 & & $\mathrm{H}$ & 12.81 & 14.06 & 15.31 \\
\hline & VH & 25.27 & 31.27 & 35.27 & & VH & 14.26 & 15.51 & 16.51 \\
\hline \multirow[t]{5}{*}{$T(\mathrm{~mm})$} & $V L$ & 6.12 & 6.72 & 7.32 & $D_{a}(m m)$ & $\mathrm{VL}$ & 15.34 & 15.44 & 15.54 \\
\hline & $L$ & 6.2 & 6.8 & 7.4 & & $\mathrm{~L}$ & 15.43 & 15.53 & 15.63 \\
\hline & M & 6.28 & 6.88 & 7.48 & & M & 15.6 & 15.7 & 15.8 \\
\hline & $\mathrm{H}$ & 6.79 & 6.93 & 8.5 & & $\mathrm{H}$ & 15.74 & 15.84 & 16.3 \\
\hline & VH & 7.971 & 8.641 & 10.63 & & VH & 16.2 & 16.74 & 16.84 \\
\hline \multirow[t]{5}{*}{$S\left(\mathrm{~cm}^{2}\right)$} & $V L$ & 5.8 & 5.89 & 5.95 & $A\left(\mathrm{~mm}^{2}\right)$ & $V L$ & 349.59 & 356.59 & 361.59 \\
\hline & $\mathrm{L}$ & 5.85 & 5.97 & 6.13 & & $\mathrm{~L}$ & 352.73 & 359.73 & 364.73 \\
\hline & M & 6.06 & 6.12 & 6.2 & & M & 357.77 & 364.77 & 369.77 \\
\hline & $\mathrm{H}$ & 6.15 & 6.24 & 6.79 & & $\mathrm{H}$ & 362.84 & 373.84 & 385.84 \\
\hline & VH & 6.69 & 7.62 & 7.82 & & $\mathrm{VH}$ & 372.6 & 383.6 & 395.6 \\
\hline
\end{tabular}

$(L)$ indicates, length, $(W)$ width, $(T)$ thickness, $(S)$ lateral surface, $\left(S_{p}\right)$ spherical, $\left(D_{g}\right)$ geometrical mean diameter, $\left(D_{\mathrm{a}}\right)$ arithmetic mean diameter,

(A) the image area.

\section{Modelling using Fuzzy Logic}

In the present investigation, the determination of selected physical properties of the cultivated and picked fava bean seeds in relation to the various moisture contents, fuzzy logic system was applied. The system was designed and set up using a MATLAB programme using the fuzzy logic application. The input of this fuzzy system is the percentage of the initial moisture content of the examined seeds $(w)$ and the outputs are some of the selected physical features of fava beans including length $(L)$, width $(W)$, thickness $(T)$, the arithmetic mean diameter $\left(D_{a}\right)$, geometrical mean diameter $\left(D_{g}\right)$, lateral surface $(S)$, spherical value $\left(S_{p}\right)$, the image area $(A)$, weight of 1000 seeds, true density $\left(D_{r}\right)$, mass density $\left(D_{b}\right)$, volume $(V)$, porosity $(e)$, filling repose angle $\left(F_{\theta}\right)$ and the angle of the repose discharge $(E)$. The triangular membership function was exploited to adjust the changes and the triangular membership function with three parameters is described by the following equations (Ganje et al. 2013):

$$
\text { triangle }(x ; a, b . c)=\left\{\begin{array}{l}
0 \quad x \leq a \\
\frac{x-a}{b-a} \quad a \leq x \leq b \\
\frac{c-x}{c-b} \quad b \leq x \leq c \\
0 \quad c \leq x
\end{array}\right.
$$

To present the rules of the fuzzy logicsystem, five membership functions were regarded for the input variable, namely very small (low) (VS) (8.25- 12.25), small (low) (S) (12.6216.62), average (middle) (A) (13.46-22.46), high $(\mathrm{H})$ (19.83-28.83), very high $(\mathrm{VH})$ (25.27-35.27).Moreover for all of the proposed membership functions of the output variables comprising of geometric characteristics (Table 1) along with properties of gravity and frictional parameters (Table 2) of the selected samples were determined.

After definition of membership functions of input and outputs (Tables 1 and 2), the five if-then rules for Mamdany Fuzzy Model with an input including moisture content $(W)$ and 15 output values including length $(L)$; width $(W)$; thickness $(T)$; arithmetic mean diameter $\left(D_{a}\right)$; geometrical mean diameter $\left(D_{g}\right)$; lateral surface $(S)$; spherical $\left(S_{p}\right)$; the image area $(A)$ weight of 1000 seeds $\left(m_{1000}\right)$; true density $\left(D_{r}\right)$; bulk density $\left(D_{b}\right)$; volume $(V)$; porosity $(e)$; filling repose angle $(f)$ and the angle of repose discharge $(E)$ have been defined as follows:

If (Moisture is $L$ ) then ( $L$ is $L$ ) ( $W$ is $L$ ) ( $T$ is $L)\left(D_{\mathrm{a}}\right.$ is $\left.L\right)($ $D_{g}$ is $\left.L\right)(S$ is $L)\left(S_{p}\right.$ is $\left.L\right)(A$ is $L)\left(m_{1000}\right.$ is $\left.L\right)\left(D_{r}\right.$ is $\left.H\right)\left(D_{b}\right.$ is $L)(V$ is $L)(e$ is $L)(\mathrm{f}$ is $L)(E$ is $L)$. (Rule 1$)$

If (Moisture is $V L)$ then $(L$ is $V L)(W$ is $V L)(\mathrm{T}$ is $V L)\left(D_{a}\right.$ is $V L)\left(D_{g}\right.$ is $\left.V L\right)(S$ is $V L)\left(S_{p}\right.$ is $\left.V L\right)(\mathrm{A}$ is $V L)\left(m_{1000}\right.$ is $\left.V L\right)\left(D_{r}\right.$ is $V L)\left(D_{b}\right.$ is $\left.V L\right)(V$ is $V L)(e$ is $V L)(f$ is $V L)(E$ is $V L)$. (Rule 2)

If (Moisture is $M$ ) then $(L$ is $M)(W$ is $M)(\mathrm{T}$ is $M)\left(D_{a}\right.$ is $M)\left(D_{g}\right.$ is $\left.M\right)(S$ is $M)\left(S_{p}\right.$ is $\left.M\right)(\mathrm{A}$ is $M)\left(m_{1000}\right.$ is $\left.M\right)\left(D_{r}\right.$ is $M)\left(D_{b}\right.$ is $\left.M\right)(V$ is $M)(e$ is $M)(f$ is $M)(E$ is $M)$. (Rule 3$)$

If (Moisture is $H$ ) then $(L$ is $H)(W$ is $H)(T$ is $H)\left(D_{a}\right.$ is $H)\left(D_{g}\right.$ is $\left.H\right)(S$ is $H)\left(S_{p}\right.$ is $\left.H\right)(\mathrm{A}$ is $H)\left(m_{1000}\right.$ is $\left.H\right)\left(D_{r}\right.$ is $H)\left(D_{b}\right.$ is $\left.H\right)(V$ is $H)(e$ is $H)(f$ is $H)(E$ is $H)$. (Rule 4$)$ 
TABLE 2. TRANGULAR MEMBERSHIP FUNCTIONS OF GRAVITY AND FRICTIONAL PROPERTIES OF FAVA BEANS USED BY FUZZY LOGIC SYSTEM IN THE SELECTED MOISTURE CONTENT RANGE (9.3-31.3)

\begin{tabular}{|c|c|c|c|c|c|c|c|c|c|}
\hline \multirow{2}{*}{$\frac{\text { Variables }}{D_{\mathrm{b}}\left(\mathrm{kg} / \mathrm{m}^{3}\right)}$} & \multirow{2}{*}{$\begin{array}{l}\text { Memberships } \\
\text { name } \\
\text { VL }\end{array}$} & \multicolumn{3}{|c|}{$\begin{array}{l}\text { Parameters of membership } \\
\text { functions }\end{array}$} & \multirow{2}{*}{$\frac{\text { Variables }}{E}$} & \multirow{2}{*}{$\begin{array}{l}\text { Memberships } \\
\text { name } \\
\text { VL }\end{array}$} & \multicolumn{3}{|c|}{$\begin{array}{l}\text { Parameters of membership } \\
\text { functions }\end{array}$} \\
\hline & & 670 & 692 & 710 & & & 23 & 23.9 & 24.2 \\
\hline & $\mathrm{L}$ & 635 & 644 & 673 & & $\mathrm{~L}$ & 24 & 24.5 & 27.5 \\
\hline & M & 622 & 631 & 640 & & M & 26 & 31.3 & 31.6 \\
\hline & $\mathrm{H}$ & 623 & 627 & 633 & & $\mathrm{H}$ & 31.5 & 31.9 & 34 \\
\hline & VH & 605 & 613 & 621 & & VH & 33 & 36.6 & 38.4 \\
\hline \multirow[t]{5}{*}{$D_{\mathrm{r}}\left(\mathrm{kg} / \mathrm{m}^{3}\right)$} & $V L$ & 1064 & 1069 & 1074 & $f$ & $V L$ & 21 & 22.1 & 23 \\
\hline & $\mathrm{L}$ & 1069 & 1074 & 1079 & & $L$ & 22 & 25.2 & 26.1 \\
\hline & M & 1084 & 1089 & 1094 & & M & 25.7 & 27.5 & 27.7 \\
\hline & $\mathrm{H}$ & 1092 & 1097 & 1102 & & $\mathrm{H}$ & 27.6 & 27.6 & 30 \\
\hline & VH & 1097 & 1102 & 1107 & & VH & 30 & 34.7 & 37 \\
\hline \multirow{5}{*}{ e (\%) } & $\mathrm{VL}$ & 31 & 35.2 & 39 & $V\left(\mathrm{~cm}^{3}\right)$ & $\mathrm{VL}$ & 15.6 & 17 & 17.8 \\
\hline & $\mathrm{L}$ & 38 & 40 & 41 & & $\mathrm{~L}$ & 17.5 & 18.1 & 19.4 \\
\hline & M & 41 & 42 & 42.4 & & M & 19 & 20 & 22 \\
\hline & $\mathrm{H}$ & 42.4 & 42.5 & 43.5 & & $\mathrm{H}$ & 21 & 23 & 25 \\
\hline & $\mathrm{VH}$ & 43 & 44.2 & 45.6 & & VH & 21 & 23 & 25 \\
\hline \multirow[t]{5}{*}{$m_{1000}(\mathrm{~g})$} & $V L$ & 1711.2 & 1791.2 & 1871.2 & & & & & \\
\hline & $\mathrm{L}$ & 1790 & 1900.4 & 2150.4 & & & & & \\
\hline & $M$ & 2090 & 2173.4 & 2190 & & & & & \\
\hline & $\mathrm{H}$ & 2200 & 2231.9 & 2290 & & & & & \\
\hline & VH & 2330 & 2410.1 & 2530 & & & & & \\
\hline
\end{tabular}

$\left(\mathrm{m}_{1000}\right)$ expresses weight of 1000 seeds, $\left(D_{\mathrm{r}}\right)$ true density, $\left(D_{\mathrm{b}}\right)$ bulk density, $(V)$ volume, $(e)$ porosity, $(f)$ filling repose angle and $(E)$ the angle of repose discharge.

If (Moisture is $V H)$ then $(L$ is $V H)(W$ is $V H)(T$ is $V H)\left(D_{a}\right.$ is $\left.V H\right)\left(D_{g}\right.$ is $\left.V H\right)(S$ is $V H)\left(S_{p}\right.$ is $\left.V H\right)(\mathrm{A}$ is $V H)\left(m_{1000}\right.$ is $\left.V H\right)\left(D_{r}\right.$ is $\left.V H\right)\left(D_{b}\right.$ is $\left.V H\right)(V$ is $V H)(e$ is $V H)(f$ is $V H)(E$ is $V H)$. (Rule 5).

Regarding the mentioned relations, the designed model in this investigation comprises of one input (moisture content of the seeds) and 15 outputs and has been constructed at Fig. 1 as well.

\section{RESULTS AND DISCUSSION}

Figures 2 and 3 present the outcomes of the fuzzy Logic system obtained using the MATLAB programme (Figs. 2 and 3). As it is obvious from the diagrams, each row is relevant to one rule and each of the columns is associated with one variable. The sixth row diagrams (of each column) pertains the consequences of all five presented rules of each parameter's response. As it could be noticed, in these outputs, all of the physical factors will be available once the moisture is suggested. For example, by providing a moisture content of $15 \%$, the physical features of the fava bean would be as follows: length $(23 \mathrm{~mm})$, width $(17 \mathrm{~mm})$, thickness $(82 / 6 \mathrm{~mm})$, arithmetic mean diameter $(8.13 \mathrm{~mm})$, geometrical mean diameter $(6.15 \mathrm{~mm})$, lateral surface $(6.01 \mathrm{~mm}$ square), spherical value $(0.605)$, the image area value $\left(361 \mathrm{~mm}^{2}\right)$; the weight of 1000 seeds $(1970 \mathrm{~g})$, true density $\left(1080 \mathrm{~kg} / \mathrm{m}^{3}\right)$, mass (bulk) density $\left(647 \mathrm{~kg} / \mathrm{m}^{3}\right)$; volume $\left(19.3 \mathrm{~cm}^{3}\right)$; porosity $(40.1 \%)$, filling repose angle $\left(24.9^{\circ}\right)$ and the angle of the repose discharge $\left(27.1^{\circ}\right)$. In the same way, by defining a special percentage of moisture content in the input (sample), we will be able to achieve all of the physical specifications in the second-order fraction. The facility and high velocity of

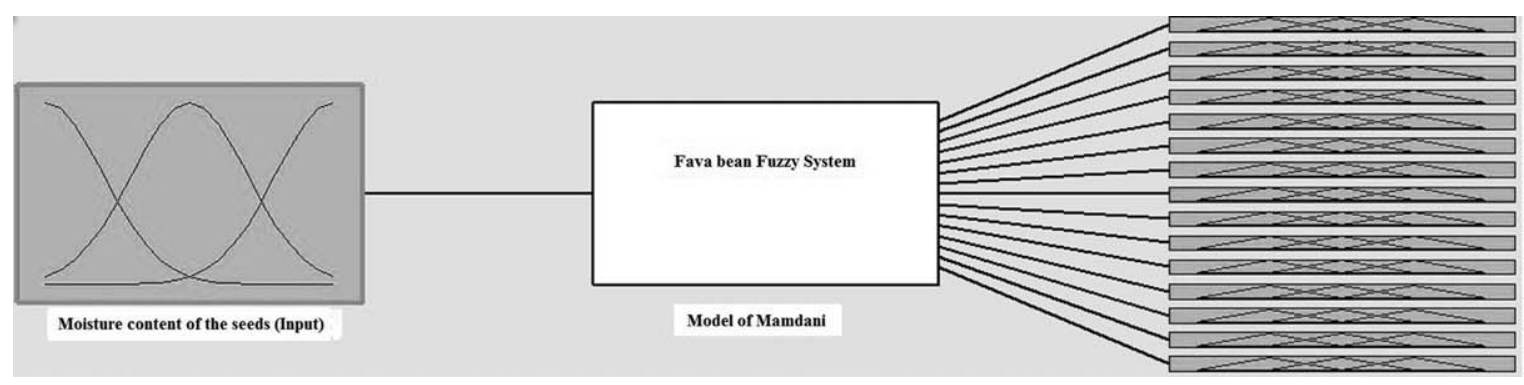

FIG. 1. THE SUGGESTED TOPOLOGY OF THE DESIGNED FUZZY LOGIC SYSTEM IN THIS INVESTIGATION 


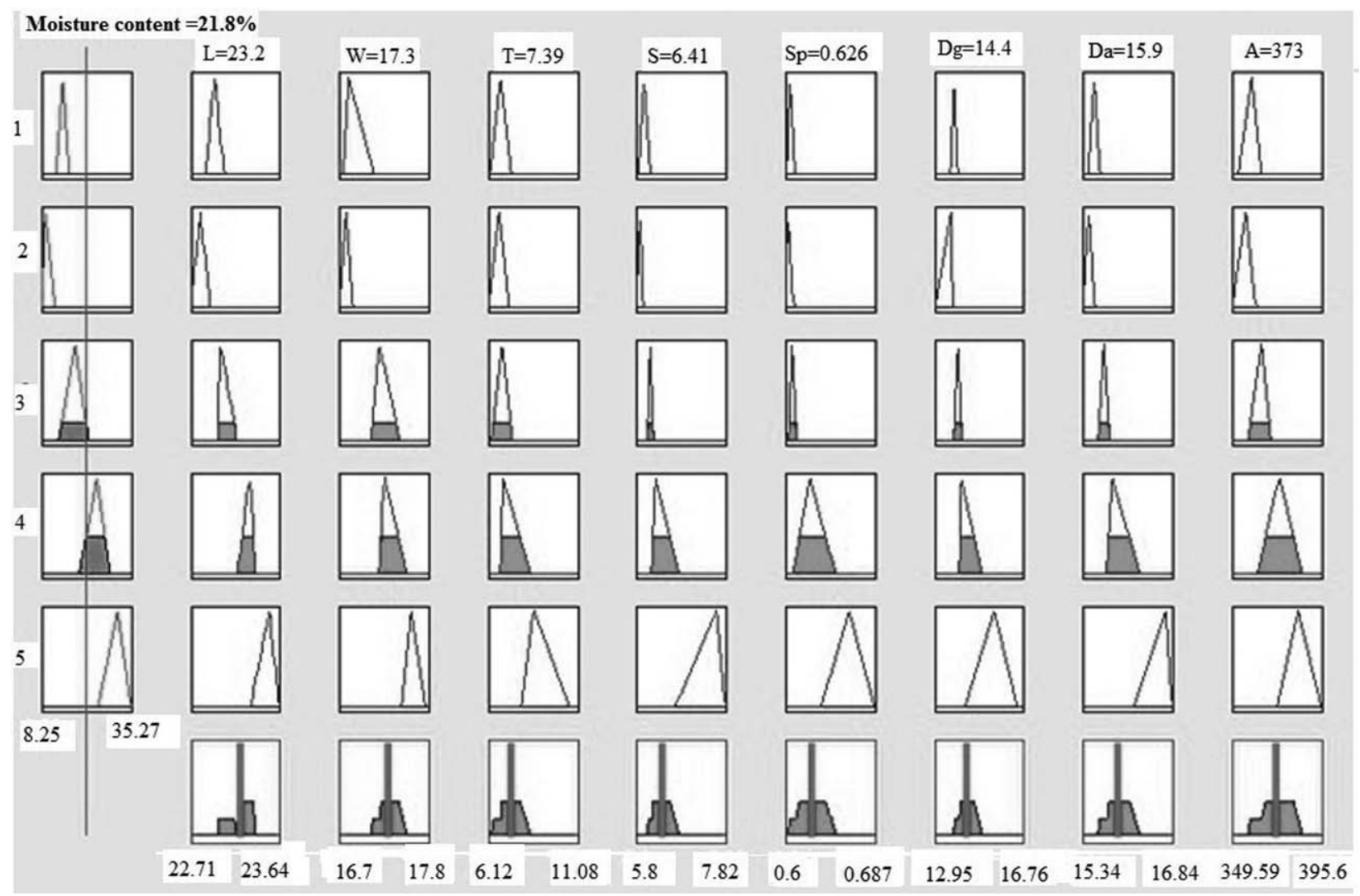

FIG. 2. THE OUTPUT OF THE PROPOSED FUZZY LOGIC SYSTEM FOR GEOMETRIC PARAMETERS

the proposed system, as well as the existence of the proper value of precision have made suitable to be used in the grading and quality control systems as well as the production lines of online evaluations.

The main objectives in the processes of various food product industries might be preserving the safety of the products and to certify the offered products without any health risks, minimizing the process period of the raw materials, as well as manufacturing products with the highest quality and lowest cost. To achieve the aforementioned objectives, access of the appropriate equipment and identification of the emerging errors during the process, and also the capabilities to qualify the online ongoing process on the products is essential. The heterogeneous nature and mutability of the exploited raw materials or ingredients, as well as the fluctuation in productions, make it complicated to control the processes of production in most food product industries, moreover, most processes performed in various food product industries are nonlinear and comprise of various dynamic times that create further complications in tracking systems in this industry. Therefore, because of the mentioned restrictions automating these types of industries, using modern computerized systems leaves them faced with problems (Haley and Mulvaney 1993).
Because of these reasons, it seems that the use of human operators in customary and manual control systems is more common. However, recent advancements in artificial intelligence such as fuzzy logicdesign and artificial neural networks (ANN) have created novel gates towards tracking diverse processes in various food industries, and might be used instead of human operators in customary systems (Tani et al. 1996). In other words, in most fields, fuzzy logicdesign could operate as a small excelsior in different environments to analyse and transfer the entered inputs to manage and control systems.

\section{Evaluating the Accuracy of the Fuzzy Logic Model}

To assess and verify the precision of the fuzzy logic model in the estimation of the physicochemical properties of fava beans, all outputs of the model were determined in two diverse input humidity values including $17 \%$ and $28 \%$, and through the same conditions, all the selected responses obtained experimentally were compared to the predicted outcomes obtained by the fuzzy logic model to provide an appropriate assessment of the model. The comparison of the correlation coefficient between the experimental and predicted response values for each of those selected humidity values (17\% and $28 \%)$ are presented in Fig. 4. As is obvious 


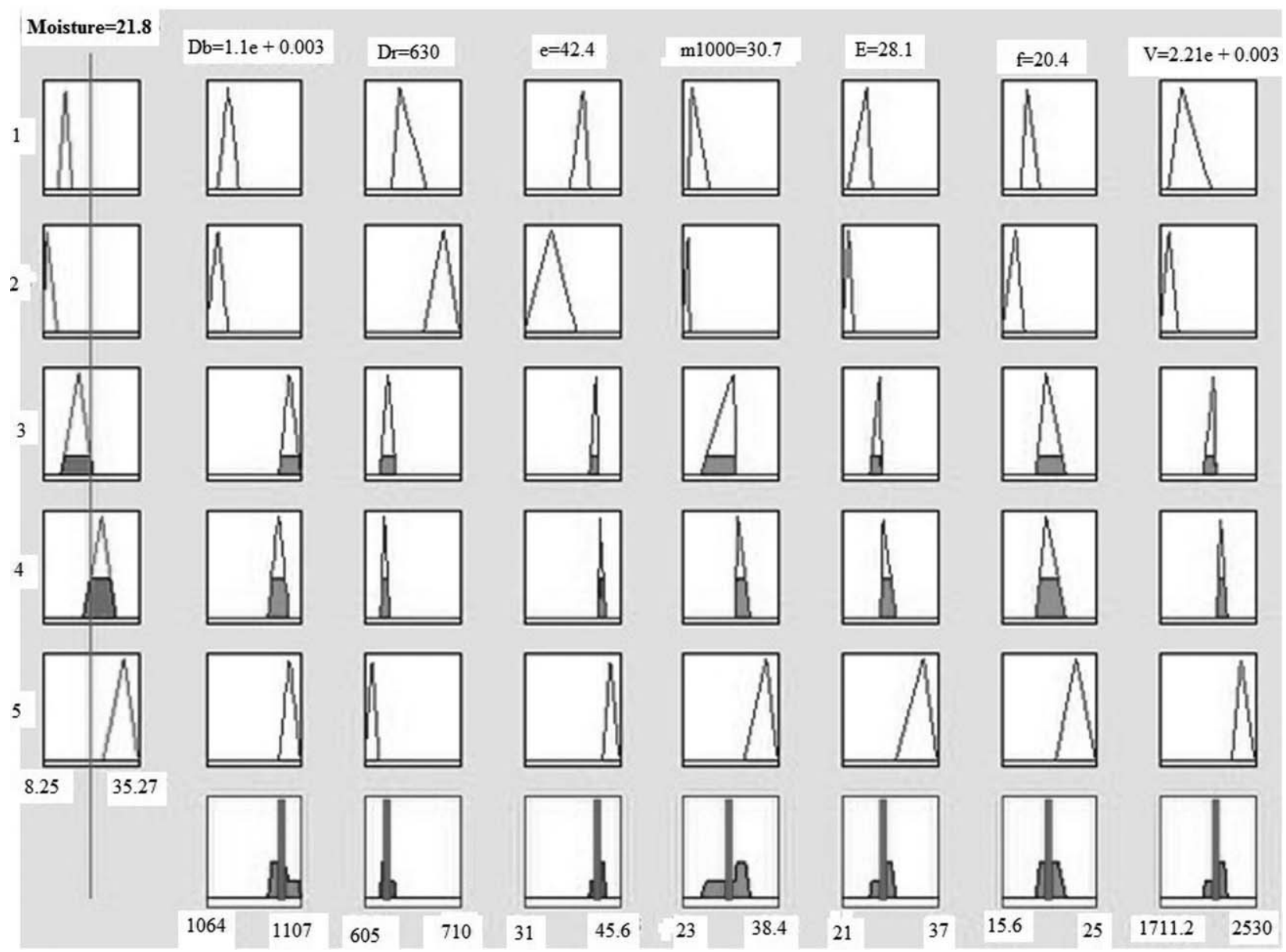

FIG. 3. THE OUTPUT OF THE PRPOSED FUZZY LOGIC SYSTEM FOR GRAVITY AND FRICTIONAL PARAMETERS

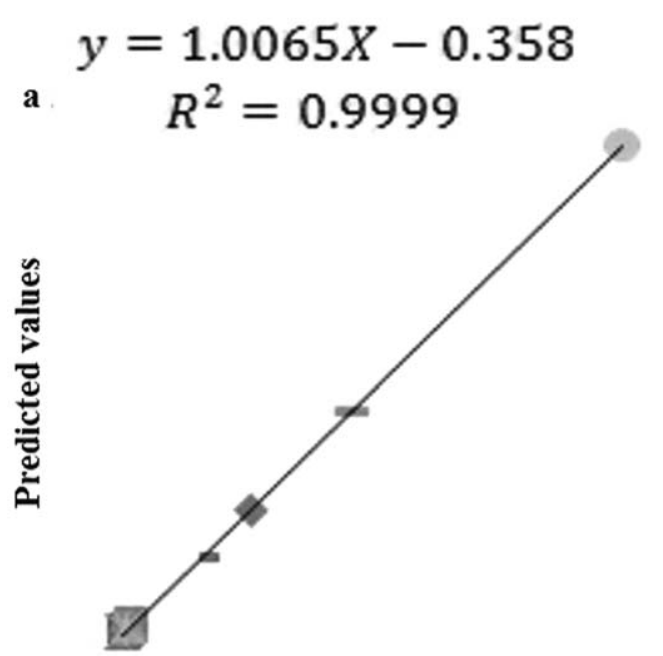

Experimental Values

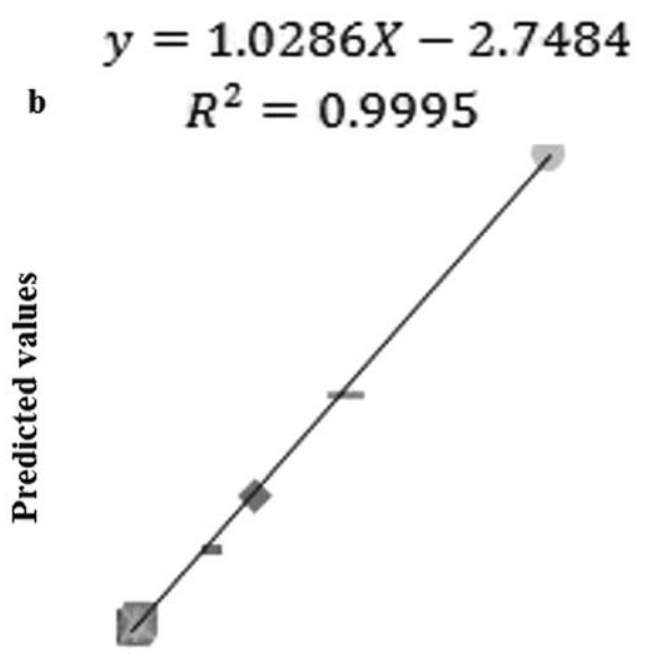

Experimental Values

FIG. 4. THE ACHIEVED CORRELATION COEFFICIENT (R2) BETWEEN THE EXPERIMENTAL AND PREDICTED VALUES OBTAINED BY FUZZY LOGIC MODEL IN THE MOISTURE CONTENTS OF 17\% (A) AND 28\% (B) OF THE SEEDS 
in Fig. 4, both of the graphs demonstrate the highest and equal correlation coefficients between the experimental and predicted values, therefore the obtained correlation coefficient between the experimental and obtained predicted values by the Fuzzy logic model $\left(R^{2}=0.9999\right.$ and 0.9995 , for the humidity values of $17 \%$ and $28 \%$, respectively) confirm the suitability and precision of the selected model in this investigation. In addition, the lower values of the mean standard deviation obtained with the selected model, including $L$ (1.23); $W$ (11.56); $T$ (1.16); $D_{a}(3.31) ; D_{g}(5.05) ; S(1.73) ; S_{p}$ (12.56); $A$ (8.60); $m_{1000}$ (1.77); $V(4.26) ; D_{r}(5.23) ; D_{b}(1.7) ;$ $E$ (2.9); $f(3.7)$ and $e$ (5.05) present the accuracy of the designed fuzzy logic model.

\section{CONCLUDING REMARKS}

Regarding the importance of control processing systems in various agricultural product industries, besides the complexity and unpredictability of the behaviors of agricultural products against diverse applied conditions during processing, the requirement of tools such as the fuzzy logic systems for predicting the behaviors of the materials used and controlling the processes seems essential and might be effectual. In the current investigation, fuzzy logic system has been applied to predict an extensive range of physical properties of fava beans in the selected moisture contents of the input seeds (9.3-31.3\%). To establish the precise of obtained fuzzy logic design, the outcomes predicted for input seed moisture contents of $17 \%$ and $28 \%$ achieved by fuzzy model were compared to the experimental values obtained for the same parameters in the same conditions and the results obtained of the comparison demonstrated higher correlation coefficient values (?0.999) between experimental and predicted values by fuzzy logic (Fig. 4), furthermore the values obtained for Mean Standard Deviation (1.23-12.56\%) have confirmed that, fuzzy logic system could be effective to design and construct a model for controlling and managing the various stages during processing including harvesting; handling; grading; preservation or storage and ... of not only fava beans but also of further possibly similar crops.

\section{ACKNOWLEDGMENT}

We are appreciating Research Centre of Agricultural Sciences of Gorgan-Golestan Province-Iran and Food Science Lab of university of Algarve for facilities and lab provided during this research.

\section{REFERENCES}

AVIARA, N.A., POWER, P.P. and ABBAS, T. 2013. Moisturedependent physical properties of Moringa oleifera seed relevant in bulk handling and mechanical processing. Ind Crops Prod. 42, 96-104.

BAGINSKY, C., PENA-NEIRA, A., CACERES, A., HEMANDEZ, T., ESTRELLA, I., MORALES, H. and PERTUZE, R. 2013. Phenolic compound composition in immature seeds of fava bean (Vicia faba L.) varieties cultivated in Chile. J Food Compost Anal. 31(1). 1-6.

BOUZEMBARK, Y. and MARVIN, H.J.P. 2016. Prediction of food fraud type using data from Rapid Alert System for Food and Feed (RASFF) and Bayesian network modelling. Food Control. 61, 180-187.

DAVIDSON, V.J., RYKS, J. and CHU, T. 2001. Fuzzy models to predict consumer ratings for biscuits based on digital image features. Fuzzy Set Syst. 9(1), 62-67.

DOLATABADI, Z., ELHAMI RAD, A.H., FARZANEH, V., AKHLAGHI FEIZABAD, S.H., ESTIRI, S.H. and

BAKHSHABADI, H. 2016. Modeling of the lycopene extraction from tomato pulps. Food Chem. 190(0), 968-973.

FAO. 2005. Production Year Book, 2004. Food and Agriculture Organization of the United Nations, Rome, Italy.

FARZANEH, V. and CARVALHO, I.S. 2015. A review of the health benefit potentials of herbal plant infusions and their mechanism of actions. Ind Crops Prod. 65(0), 247-258.

GANJE, M., JAFARI, S.M., GHANBARI, V., DEZYANI, M., EZZATI, R. and SOLEIMANI, M. 2013. Modeling the drying kinetics of onion in a fluidized bed drier equipped with a moisture controller using regression, fuzzy logic and artificial neural networks methods (In Persian). Iran J Nutr Sci Food Technol. 7 (5), 399-407

GOEL, N. and SEHGAL, P. 2015. Fuzzy classification of preharvest tomatoes for ripeness estimation - An approach based on automatic rule learning using decision tree. Appl Soft Comput. $36,45-56$.

HALEY, T.A. and MULVANEY, S.J. 1995. Advanced Process Control Techniques for the Food Industry. Trends Food Sci Technol. 6(4),103-110.

JOSEPH, M. 1997. ASAE S352.2. Moisture MeasurementUngroundGrain and Seeds, ASAE standards vol. 555.

KALEEMULLAH, S. and GUNASEKAR, J.J. 2002. PH-postharvest technology: Moisture-dependent physical properties of arecanut kernels. Biosyst Eng. 82(3), 331-338.

KUKIC, D.V., SCIBAN, M.B., PRODANOVIC, J.M., TEPIC, A.N. and VASIC, M.A. 2015. Extracts of fava bean (Vicia faba L.) seeds as natural coagulants. Ecol Eng. 84, 229-232.

NAKAGAWA, K. and OCHIAI, T. 2015. A mathematical model of multi-dimensional freeze-drying for food products. J Food Eng. 161, 55-67.

PERROT, N., TRYSTRAM, G., GUELY, F., CHEVRIE, F., SCHOESSTTERS, N. and DUGRE, E. 2000. Feed-back Quality Control in the Baking Industry Using Fuzzy Sets. J Food Process Eng. 23, 249-279.

RAZAVI, M.A. and AKBARI, R. 2009. Biophysical Properties of Agricultural and Food Products (In Persian). Ferdowsi University of Mashhad Publication, Mashhad, Iran. 
RAZAVI, M.A., ZAYERZADEH, A., KHAFAJI, N. and PAHLEVANI, M. 2010. Evaluation of some of the physical properties and seed desi varieties (In Persian). Bean's Research of Iran. 1(1), 7.

ROMULI, S., KARAJ, S. and MULLER, J. 2015. Influence of physical properties of Jatropha curcas L. seeds on shelling performance using a modified disc mill. Ind Crops Prod. 77, 1053-1062. ROSTAMI, M., FARZANEH, V., BOUJMEHRANI, A., MOHAMMADI, M. AND BAKHSHABADI, H. 2014. Opti- mizing the extraction process of sesame seed's oil using response surface method on the industrial scale. Ind Crops Prod. 58(0), 160-165.

TANI, T., MURAKOSHI, S. and UMANO, M. 1996. Neuro-fuzzy hybrid control system of tank level in petroleum plant' in IEEE Trans. Fuzzy Set Syst. 4(9), 360.

TSCHEUSCHNER, H.D. 1987. Physical properties of plant and animal materials. structure, physical characteristics and mechanical properties. Food / Nahrung. 31(7), 702-702. 